\title{
Assessment of thyroid function during and after treatment of thyrotoxicosis
}

\author{
D. G. MCLARTY AND W. D. ALEXANDER \\ From the Department of Medicine, Gardiner Institute, Western Infirmary, Glasgow
}

Before treatment of thyrotoxicosis has started it is not possible at present to foretell which patients will experience a protracted illness and which will promptly recover. The aim of assessment during treatment of thyrotoxicosis is to define which course the disease is running and consequently whether antithyroid drugs or destructive therapy will be the more appropriate.

\section{Basis of Plan of Management}

Destructive therapy for thyrotoxicosis frequently results in hypothyroidism, necessitating life-long treatment with thyroxine. Antithyroid drug therapy is followed by remission in a considerable proportion of patients and subsequent clinical hypothyroidism is rare. There thus seems to be a strong case for the use of antithyroid drugs as the initial treatment in most thyrotoxic patients under the age of 45 years. Beyond the age of 45 or 50 years the risk of cardiac problems increases.

The plan of treatment proposed is an interim one based on data obtained in a prospective study of 105 patients followed for more than four years (Alexander, McLarty, Horton, and Pharmakiotis, 1973).

Thyrotoxicosis followed one of three courses: remission after one course of antithyroid drugs (group 1, 43 patients, $41 \%$ ); persistent thyrotoxicosis (group 3, 43 patients, $41 \%$ ), in these patients either the disease was active more than four years after the start of antithyroid drug therapy (36 patients) or thyrotoxicosis had persisted for two to four years before subtotal thyroidectomy (seven patients); an intermediate group (group 2, 19 patients, $18 \%$ ).

We suggest, therefore, the use of antithyroid drugs in the majority of patients with Graves' disease under 45 years of age, coupled with repeated assessment of the response to treatment at sixmonthly intervals (Alexander et al, 1973; Goolden, Williams, and Thalassinos, 1973). Every six months a decision, based on clinical assessment together with evidence from the tests of thyroid function, is taken to follow one of three courses of action: to continue with antithyroid drugs, to arrange destructive therapy, or to stop antithyroid drugs if the disease has remitted. In many patients the disease will remit as shown by a return of normal thyroidal suppressibility. In order to assess the development of thyroidal suppressibility, triiodothyronine $\left(\mathrm{T}_{3}\right)$ in a dose of $80 \mu \mathrm{g}$ daily is given in conjunction with carbimazole.

In the interim plan described below the choice of the form of destructive therapy (surgery or radioiodine) is assumed to follow conventional lines (Wayne, 1960; McGirr, 1972).

\section{Plan of Management for Thyrotoxic Patients under 45 Years of Age}

WHEN THE PATIENT IS FIRST SEEN (FIG 1)

Carry out clinical examination and assess goitre size, measure 20-minute ${ }^{132} \mathrm{I}$ thyroid uptake, measure free thyroxine index (FTI), perform thyroid scan.

Either start treatment with antithyroid drugs and $T_{3}$, or arrange destructive therapy (subtotal thyroidectomy or ${ }^{131} \mathrm{I}$ ) if the patient has other serious disease, a large disfiguring goitre above $100 \mathrm{~g}^{1 *}$, relapse after thyroidectomy, thyrocardiac disease, or hyperthyroidism associated with functioning nodule(s). At subsequent six-monthly assessments repeat the 20-minute ${ }^{132}$ I uptake, the FTI and the assessment of goitre size. In the first year FTl is also measured at three and nine months.

AFTER SIX MONTHS' TREATMENT WITH ANTITHYROID DRUGS (FIG 2)

Change to destructive therapy if the 20-minute ${ }^{132}$ I uptake has risen, ${ }^{2}$ is above $30 \%, 3$ or has not suppressed by $50 \%$ of the control value 4 .

Continue with antithyroid drugs for a further six months if the 20-minute ${ }^{132}$ I uptake has fallen by more than $50 \%$ of the control value, or is less than $8 \%$.

*Superscripts refer to numerals in table. 


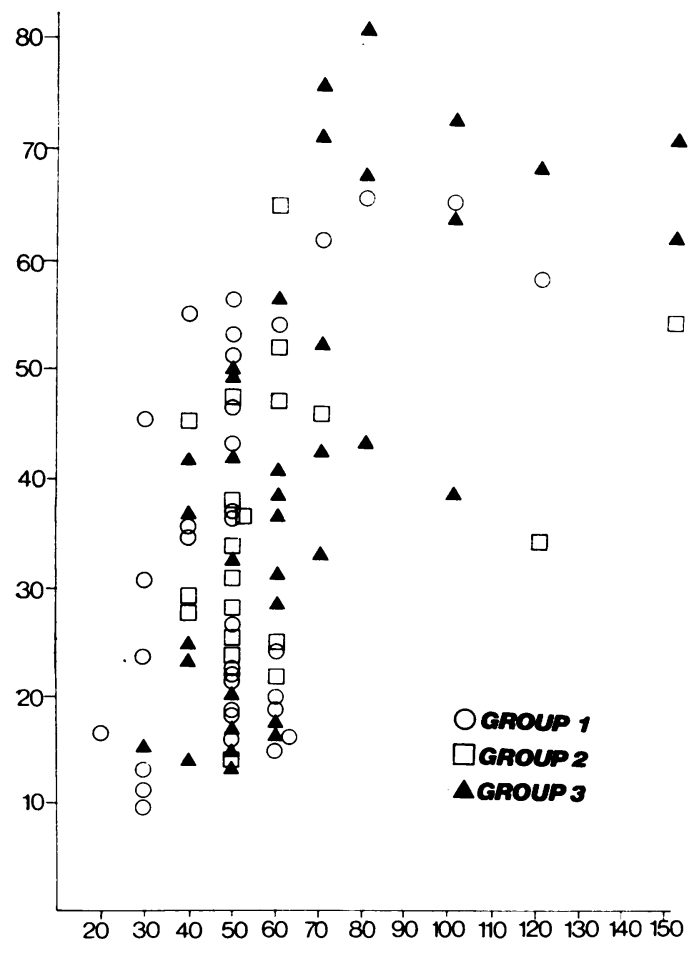

Fig 1

\section{MUN "MI UPTAKE \%}

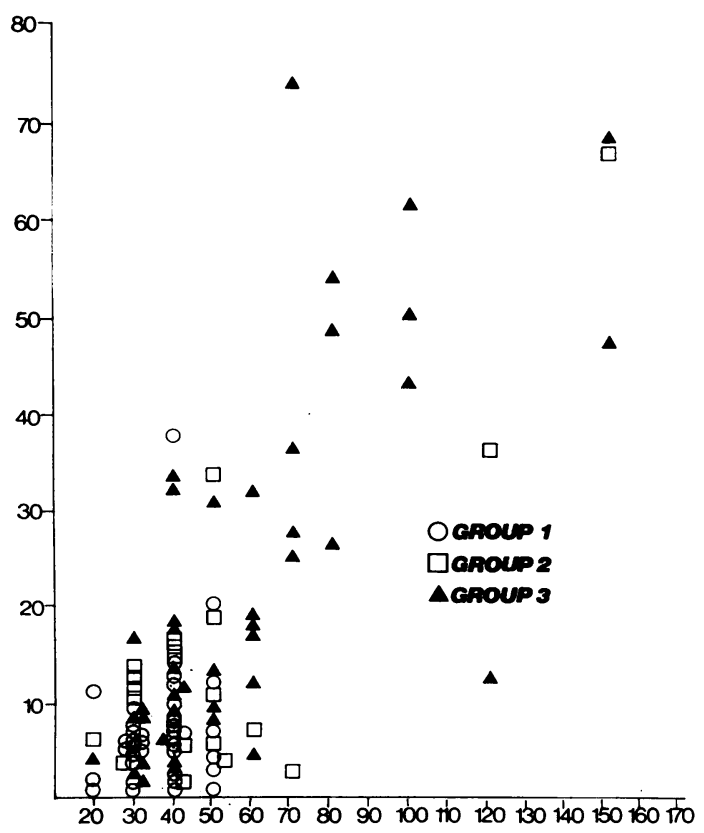

Fig 3

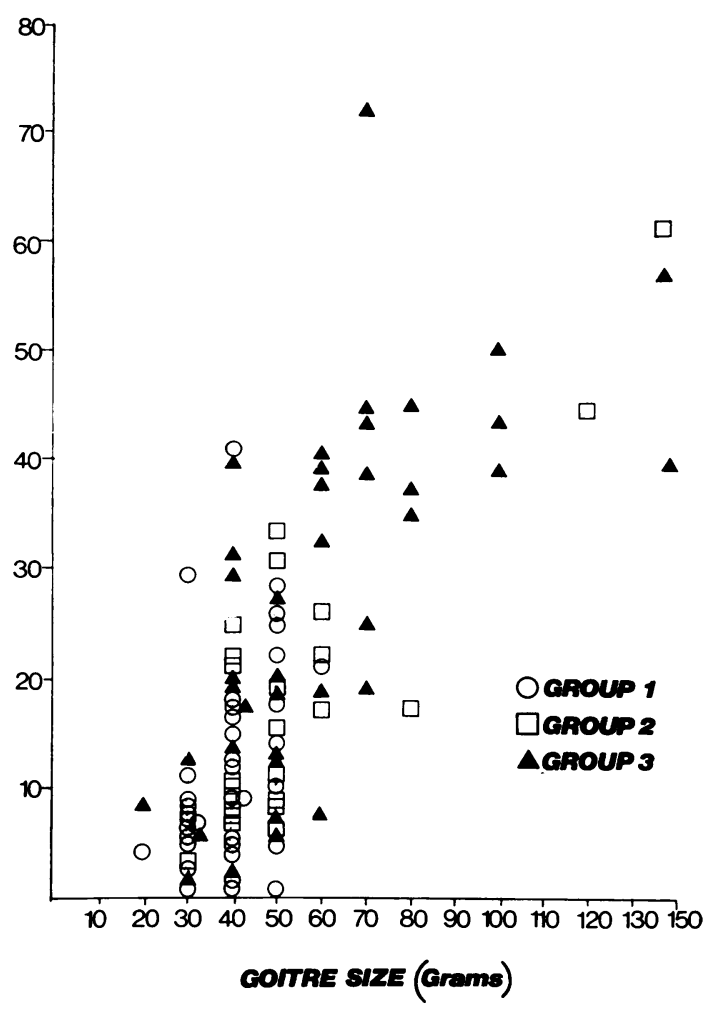

Fig 2

Fig 1 Relationship between goitre size and 20-minute ${ }^{132}$ I uptake in groups 1, 2, and 3 before the start of treatment.

Fig 2 Relationship between goitre size and 20-minute ${ }^{132}$ I uptake in groups 1,2, and 3, six months from the start of treatment.

Fig 3 Relationship between goitre size and 20-minute ${ }_{132}$ I uptake in groups 1, 2, and 3,12 months from start of treatment. 
AFTER 12 MONTHS' TREATMENT WITH ANTITHYROID DRUGS (FIG 3)

Change to destructive therapy if the 20-minute ${ }^{132} \mathrm{I}$ uptake is above $15 \%$ and/or the goitre is more than twice the normal thyroid size? ${ }^{7}$, measurement of circulating levels of thyroid hormone and enquiry reveal that the patient is not taking tablets regularly.

Continue with antithyroid drugs for a further six months if the 20-minute ${ }^{132}$ I uptake is between 8 and $15 \%$, and the goitre is not more than twice the normal thyroid size.

Stop antithyroid drugs if the 20-minute 132I uptake is below $8 \%^{8}$.

\section{AFTER 18 MONTHS' TREATMENT WITH ANTI- THYROID DRUGS \\ Change to destructive therapy if the 20-minute 132I uptake is above $15 \% \%^{9}$. Continue with anti- thyroid drugs for a further six months if the 20- minute ${ }^{132} \mathrm{I}$ uptake is between 8 and $15 \%$. \\ Stop antithyroid drugs if the 20-minute 132 I uptake is less than $8 \%$.}

AFTER 24 MONTHS' TREATMENT WITH ANTITHYROID DRUGS

Change to destructive therapy if 20-minute ${ }^{132}$ I uptake is above $15 \% 10$. Stop therapy otherwise.
When antithyroid drugs are discontinued after 12,18 , or 24 months, triiodothyronine ( $80 \mu \mathrm{g}$ daily) is continued, to determine whether thyroidal suppressibility continues or not. At this stage serial measurement of the free thyroxine index or PBI provides an adequate indication of the underlying functional state of the thyroid, and is continued six monthly for a further two years. Thereafter, assessment of thyroid status is carried out annually, since recurrence has been observed in one patient as long as 22 years after a first course of treatment with antithyroid drugs.

If hyperthyroidism recurs in those patients in whom thyroidal suppressibility had returned, antithyroid drugs are restarted and a decision whether or not to change to destructive therapy, continue with antithyroid drugs or stop treatment is again taken every six months on the same plan as before. If relapse follows two courses of antithyroid drugs, destructive therapy is carried out.

Relapse occurred in eight patients in whom the 20-minute ${ }^{132}$ I uptake had fallen to less than $8 \%$ and in whom treatment was discontinued before 12 months from the start of treatment. This suggests that even if the 20 -minute uptake falls below $8 \%$, it may be advisable to continue antithyroid drug therapy in such patients for $\mathbf{1 2}$ months.

This plan of management is an interim one, and

\begin{tabular}{|c|c|c|c|c|c|c|}
\hline \multirow{2}{*}{$\begin{array}{l}\text { Text } \\
\text { Reference No. }\end{array}$} & & \multicolumn{3}{|c|}{ Group } & \multirow{2}{*}{$\begin{array}{l}\text { Relapse after } \\
\text { First Course }\end{array}$} & \multirow{2}{*}{$\begin{array}{l}\text { Probability of } \\
\text { Relapse after } \\
\text { First Course }\end{array}$} \\
\hline & & 1 & 2 & 3 & & \\
\hline 1 & $\begin{array}{l}\text { Pretreatment goitre size } 100 \mathrm{~g} \\
\text { or more }\end{array}$ & 2 & 2 & 8 & 10 & 0.83 \\
\hline 2 & $\begin{array}{l}\text { Increase in 20-min uptake during } \\
\text { first six months on carbimazole } \\
\text { and } T_{3}\end{array}$ & 0 & 3 & 4 & 7 & 1.00 \\
\hline 3 & $\begin{array}{l}\text { 20-Min }{ }^{132} \mathrm{I} \text { uptake } 30 \% \text { or more } \\
\text { after } 6 \text { months on carbimazole and } T_{3}\end{array}$ & 1 & 3 & 18 & 21 & 0.95 \\
\hline 4 & $\begin{array}{l}\text { 20-Min uptake more than } 50 \% \\
\text { of control value after } 6 \text { months } \\
\text { on carbimazole and } T_{3}\end{array}$ & 7 & 6 & 21 & 27 & 0.79 \\
\hline 5 & $\begin{array}{l}\text { 20-Min uptake less than } 50 \% \text { of } \\
\text { control value after } 6 \text { months on } \\
\text { carbimazole and } T_{3}\end{array}$ & 27 & 11 & 11 & 22 & 0.45 \\
\hline 6 & $\begin{array}{l}20 \text {-Min }{ }^{132} \text { I uptake } 15 \% \text { or more } \\
\text { after } 12 \text { months from the start of } \\
\text { treatment }\end{array}$ & 2 & 5 & 22 & 27 & 0.93 \\
\hline 7 & $\begin{array}{l}\text { Goitre more than twice normal } \\
\text { size at } 12 \text { months }\end{array}$ & 0 & 4 & 19 & 23 & 1.00 \\
\hline 8 & $\begin{array}{l}20 \text {-Min }{ }^{132} \text { I uptake less than } 8 \% \\
12 \text { months from the start of } \\
\text { treatment }\end{array}$ & 29 & 9 & 10 & 19 & 0.39 \\
\hline 9 & $\begin{array}{l}20 \text {-Min }{ }^{132} \mathrm{I} \text { uptake } 15 \% \text { or more } \\
18 \text { months from the start of } \\
\text { treatment }\end{array}$ & 1 & 11 & 24 & 35 & 0.97 \\
\hline 10 & $\begin{array}{l}20 \text {-Min }{ }^{132} \text { I uptake } 15 \% \text { or more } \\
24 \text { months from the start of } \\
\text { treatment }\end{array}$ & 0 & 6 & 13 & 19 & 1.00 \\
\hline
\end{tabular}

Table Relation between selected features and probability of relapse in a series of 105 thyrotoxic patients (Alexander et al, 1973) 
will require to be tested. Since also the normal radioiodine uptake may vary in different parts of the world and even within the same region (Stanbury, 1969; Pittman, Dailey, and Beschi, 1969), it may be necessary for each centre to establish 20-minute 132I uptake values which correspond with those mentioned in this interim plan. Similar guidelines based on 20-minute ${ }^{99 \mathrm{~m}} \mathrm{TC}$ uptakes will also have to be established by those clinics who use it rather than ${ }^{132}$ I. Measurement of the 20-minute uptake now makes it possible to follow the course of Graves' disease during treatment with antithyroid drugs and to plan treatment accordingly. We recommend that destructive therapy be carried out after two years if the thyroid gland has remained continuously hyperactive. However, since remission may occur beyond this period of time, some physicians might wish to continue antithyroid drugs beyond 24 months. This may be of particular relevance in children and adolescents, since the results of treatment with thyroidectomy and ${ }^{131}$ I are unsatisfactory and associated with a high morbidity (Reeve, Hales, White, Thomas, and Hunt, 1969; Starr, Jaffe, and Oettinger, 1969). Since the results of antithyroid drug treatment are no different in older age groups, there may be a case for extending the age limit beyond 45 years in some cases, and making a decision whether or not to proceed with destructive therapy after a period of six months on antithyroid drugs.

\section{Long-term Follow Up}

Patients who have received treatment for thyro- toxicosis may have a recurrence or develop hypo $\frac{\overrightarrow{0}}{9}$ thyroidism even after several years. Therefore:

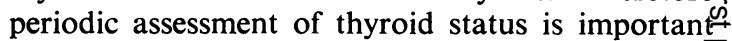
and it should probably be life-long. Increasing experience of a computer-assisted follow-up system들. (using clinical examinations and PBI) has con firmed the initial impression that this simple arrange ment achieves advantages for the patient, the generafs practitioner, and the hospital clinic (Boyle, 1974) $\vec{\nabla}$ Measurement of serum TSH may provide a usefuladditional index of hypothyroidism when its exactw role has been better defined.

\section{References}

Alexander, W. D., McLarty, D. G., Horton, P., and Pharmakiotis A. D. (1973). Sequential assessment during drug treatment of thyrotoxicosis. Clin. Endocr., 2, 43-50.

Boyle, C. M. (1974). The Scottish automated follow-up register four years' Glasgow experience. Brit. med. J., 2, 490.

Goolden, A. W. G., Williams, E. D., and Thalassinos, N. C. (1973) Studies of thyroid function using ${ }^{9} \mathrm{~T} \mathrm{~cm}$ in thyrotoxic patients during treatment with antithyroid drugs. Clin. Endocr., $2 \stackrel{?}{\supset}$ 65-73.

McGirr, E. M. (1972). The pathogenesis and treatment of thyrotoxi cosis. In Modern Trends in Endocrinology, 4, edited by F. T. GN Prunty and H. Gardiner-Hill, pp. 221-249. Butterworths' L.ondon.

Pittman, J. A., Jr., Dailey, G. E., III, and Beschi, R. J. (1969) Changing normal values for thyroidal radioiodine uptake New Engl. J. Med., 280, 1431-1434.

Reeve, T. S., Hales, I. B., White, B., Thomas, I. D., and Hunt, P. SД్ (1969). Thyroidectomy in the management of thyrotoxicosion in the adolescent. Surgery, 65, 694-699.

Stanbury, J. B. (1969). The changing iodide-uptake test. New Engl $\overrightarrow{\vec{\sigma}}$ J. Med., 280, 1474-1475.

Starr, P., Jaffe, H. L., and Oettinger, L., Jr. (1969). Later results of 1311 treatment of hyperthyroidism in 73 children and adolescents: 1967 follow up. J. nucl. Med., 10, 586-590.

Wayne, E. J. (1960). Clinical and metabolic studies in thyroid disease Brit. med. J., 1, 1-11 and 78-90. 